\title{
The Empirical Research on Sustainable Development of the Industrial Undertaking Area in Yangtze River Economic Belt-Take Jingmen City of Hubei Province as an Example
}

\author{
Zhang Zhihui ${ }^{1,2}$, Jiang Zichun ${ }^{1}{ }^{*}$, Huang Ping ${ }^{1}$, Liu Jian ${ }^{1}$, Wang Xiaoyan ${ }^{1}$ \\ ${ }^{1}$ Remote Sensing Application Institute, Agricultural Sciences Academy of Sichuan, Chengdu, China \\ ${ }^{2}$ Economics and Management College, Panzhihua College, Panzhihua, China \\ Email address: \\ 249415656@qq.com (Zhang Zhihui),285668297@qq.com (Jiang Zichun) \\ ${ }^{*}$ Corresponding author
}

To cite this article:

Zhang Zhihui, Jiang Zichun, Huang Ping, Liu Jian, Wang Xiaoyan. The Empirical Research on Sustainable Development of the Industrial Undertaking Area in Yangtze River Economic Belt-Take Jingmen City of Hubei Province as an Example. Agriculture, Forestry and Fisheries. Vol. 9, No. 4, 2020, pp. 105-112. doi: 10.11648/j.aff.20200904.12

Received: June 8, 2020; Accepted: June 23, 2020; Published: July 4, 2020

\begin{abstract}
Objective] It has been included into national strategy that we are going to exploit the Yangtze river basin, promote the industrial gradient transfer, and realize sustainable development, to form the new economic supporting belt of China. Industrial undertaking zone is the key area to the sustainable development of the Yangtze River economic belt. Studying quantitatively the regional ecological environment pressure, calculating the threshold value of sustainable development can provide decision-making reference for transforming the development mode of the Yangtze River economic belt and realizing sustainable development. [Method] Dynamically analyze the sustainable development situation from 2006 to 2014 in the demonstration undertaking area of Jing-men city using the ecological footprint model, And comparatively study the current development situation of industrial undertaking areas under provincial scale. [Result] During the sample period, the ecological deficit and ecological pressure in demonstration area continue increasing at first, and the coordination becomes gradually poor, the peak appears in 2012, then the pressure release, coordination begins to recover gradually, resource utilization is becoming efficient. The relation of GDP and ecological footprint fits for typical Kuznets inverted U curve. Undertaking area and demonstration area both highlight the characteristics of "high pressure, low coordination, low development level". [Conclusion] Put forward the suggestions of carrying out the main function area planning, improving the ecology efficiency of industry and resource allocation efficiency, etc. to cross the inflection point of Kuznets inverted $U$ curve with a lower ecological footprint level, and realize sustainable development.
\end{abstract}

Keywords: Yangtze River Economic Belt, Industrial Undertaking Area, Ecological Footprint, Sustainable Development, Kuznets Inverted U Curve

\section{Introduction}

The coastal economic belt and the Yangtze river economic belt constitute the T-shaped spatial structure, which accurately reflects the economic strength and development potential of China's land and resources [1]. The development and construction of the T-type economic belt can drive the sustainable development of the national economy [2]. In the 1980 s, China took the lead in launching the strategy of opening up and developing the coastal economic belt and made great achievements. However, the Yangtze economic belt has been put on hold at the national strategic level. No matter the per capita economic development index or the industrial structure, its development level is currently lower than that of coastal areas. However, the economic development potential of the Yangtze River economic belt is huge. According to Academician Lu Da-dao, only the development potential of regions below Nanjing in Yangtze river economic belt is equivalent to that of two coastal economic belts. China's macro-economy has entered the "new normal", resource environment constraints are tightening, world economic recovery is lack of strength, and international 
market is weakening. China needs to develop the Yangtze river basin to form a new economic growth pole. On September 12, 2014, the state council issued the Guidance on Promoting the Development of the Yangtze River Economic Belt by Relying on the Golden Waterway. On January 7, 2016, general secretary Xi Jing-ping stressed at the symposium on promoting the development of the Yangtze river economic belt that restoring the ecological environment of the Yangtze river should be given an overwhelming position, that the east and the west should complement each other by taking advantage of their comparative advantages, and that industries should be transferred from the east to the central and western regions to achieve sustainable development. Industry will continue to be the economic backbone of the Midwest for a long time to come, and industry is a major source of serious ecosystem degradation [3] Industrial eco-efficiency in the east is much higher than in the Midwest [4] At the same time, great resource and environmental costs have been paid in the process of industrialization in the central and western regions due to various reasons. The severe challenges facing the sustainable development of the Yangtze river economic belt mainly come from the central and western regions. Quantitative understanding of the utilization status of its natural resources and measuring whether the future demand is within the "ecological red line" have become the core of the research on sustainable development of the whole economic belt. In this paper, Jing-men City is selected as the research object, and the ecological footprint theory proposed by Professor W. Rees, Canadian ecological economist is applied. It dynamically analyzed the ecological footprint and ecological carrying capacity in 2006-2014 and measured Jing-men "industrial transfer demonstration zone" to achieve the threshold of sustainable development. It is of great significance to the development of the Midwest of the Yangtze River economic belt and provides decision-making reference for the Yangtze River economic belt to actively adapt to the new normal, "stabilize growth", "adjust structure" and actively change development mode.

\section{Material and Method}

\subsection{Overview of the Case Study Area}

Spanning the eastern and western parts of China, the Yangtze economic belt covers an area of more than 2 million square kilometers, accounting for more than one-fifth of China's land mass, Covering 11 provinces and cities, including Shanghai, Jiangsu, Zhejiang, Anhui, Jiangxi, Hubei, Hunan, Guizhou, Sichuan, Chongqing and Yunnan, it is one of the most important industrial corridors and the first place in terms of agricultural foundation in China. Jing-men, Hubei province, is the "waist" of the Yangtze river economic belt, with a land area of $12404 \mathrm{~km}^{2}, 111^{\circ} 51^{\prime} \mathrm{E}-113^{\circ} 29^{\prime} \mathrm{E}, 30^{\circ} 28^{\prime} \mathrm{N}-31^{\circ} 36^{\prime} \mathrm{N}$, it has the north sub-tropical monsoon climate and diverse landform. Its mountain, hill, plain and water network are distributed in steps, and its soil types are various and suitable for the growth of various crops. As the "industrial transfer demonstration zone" in the strategy of "central rising", its development is very representative in the central and western regions of the Yangtze river economic belt.

\subsection{Research Technique}

\subsubsection{Ecological Footprint Model}

Ecological footprint is a mutually exclusive space with biological production capacity to consume resources and absorb wastes, which is needed by human beings to maintain the current living standard of people in a specific region [5]. Ecological carrying capacity refers to the area of bio-productive land provided by nature for human in the region [6], Land can be divided into six types: arable land, forest land, water area, grassland, building land and fossil fuel land, and can be compared by conversing of all kinds of land into global hectares through equilibrium factors and yield factors. General formula for calculating per capita ecological footprint [7] is ef $=\sum_{1}^{6} r_{i}\left(\frac{c_{i}}{p_{i}}\right)$ (1). ef is the per capita ecological footprint $\left(\mathrm{hm}^{2}\right) ; r_{i}$ is the equilibrium factor; $c_{i}$ is kind of consumption item per capita consumption $(\mathrm{kg}) ; p_{i}$ is the global average annual production capacity of the consumption project $\left(\mathrm{kg} / \mathrm{hm}^{2}\right)$; General formula of ecological load capacity per capita [7]: ec $=\sum_{1}^{6} a_{i} y_{i} r_{\mathrm{i}}$ (2). Per capita ecological carrying capacity is ec, actual per capita possession of the kind of biological production land area is $a_{i}\left(\mathrm{hm}^{2}\right), r_{i}$ is the equilibrium factor and $y_{i}$ is the yield factor. Formula for calculating ecological deficit/surplus per capita is ed $=$ ec - ef (3).

\subsubsection{Data and Parameter Selection}

The basic data came from City Statistics Yearbook of China, China Rural Statistical Yearbook, Statistical Yearbook of Hubei Province and Statistical Yearbook of Jing-men City. Part of the data comes from reports of relevant departments of Jing-men government and survey. The equilibrium factor come from National Footprint Accounts 2012 of WWF, arable and building land 2.51, woodland 1.26, grassland 0.46 , water area 0.37 , Fossil energy land 1.26. Yield factors are come from literature, arable and building land 2.24, woodland 3.29, grassland 1.2, water area 1.00 [8].

\section{Conclusion and Analysis}

\subsection{Calculation and Dynamic Analysis of Ecological Footprint per Capita in Jing-men City}

We directly use consumption data of Jing-men city without considering the impact of trade when calculating the ecological footprint. The per capita ecological footprint is obtained according to formula (1) (table 1), the per capita ecological footprint of Jing-men city showed a rapid rise and then a sharp decline. It rose from $3.2954 \mathrm{hm}^{2}$ in 2006 to $8.5630 \mathrm{hm}^{2}$ in 2012 , with a net increase of $5.2676 \mathrm{hm}^{2}$ in six 
years, and the average annual growth rate is $0.878 \mathrm{hm}^{2}$, that's up $159.8 \%$. GDP rose $213.2 \%$, from 108.526 billion to 34.654 billion yuan. In 2013, the ecological footprint began to decline, and it dropped to $5.8858 \mathrm{hm}^{2}$ in 2014 , with a two-year decline of $2.677 \mathrm{hm}^{2}$, an average annual decline of $1.335 \mathrm{hm}^{2}$, a decrease of $31.3 \%$. GDP grew from 108.526 billion in 2012 to 131.059 billion yuan in 2014, up 20.8\%. Economic growth and ecological footprint trend reverse. The fitting quadratic curve of ecological footprint in the sample period (figure 1) is $Y=-0.1272 x^{2}+1.6969 x+1.814 \quad\left(R^{2}=0.756\right)$ and fits Kuznets inverted $U$ curve. The turning point of the ecological footprint is consistent with the initial results achieved in Jing-men's efforts to develop circular economy in 2012 (it was included in the national circular economy demonstration city in 2013) and the transformation of economic development mode.

Table 1. Components of per capita ecological footprint of Jing men in 2006-2014.

\begin{tabular}{|c|c|c|c|c|c|c|c|c|c|c|}
\hline $\begin{array}{l}\text { Land type } \\
\left(\mathrm{hm}^{2}\right)\end{array}$ & $\begin{array}{l}\text { Equilibrium } \\
\text { factors }\end{array}$ & 2006 & 2007 & 2008 & 2009 & 2010 & 2011 & 2012 & 2013 & 2014 \\
\hline Arable land & 2.51 & 0.1968 & 0.1586 & 0.1725 & 0.1669 & 0.1537 & 0.1405 & 0.1280 & 0.1240 & 0.1225 \\
\hline Grassland & 0.46 & 0.1778 & 0.3189 & 0.1559 & 0.1693 & 0.1758 & 0.1931 & 0.1830 & 0.1920 & 0.2111 \\
\hline Water area & 0.37 & 0.1482 & 0.4053 & 0.1519 & 0.1398 & 0.1614 & 0.1762 & 0.1624 & 0.1673 & 0.1736 \\
\hline Woodland & 1.26 & 0.0521 & 0.0746 & 0.0688 & 0.0745 & 0.0504 & 0.0573 & 0.0635 & 0.0641 & 0.0647 \\
\hline Building & 2.51 & 0.3894 & 0.3853 & 0.3867 & 0.3869 & 0.3934 & 0.4033 & 0.4141 & 0.3981 & 0.3886 \\
\hline Fossil energy & 1.26 & 2.3311 & 3.6887 & 4.8159 & 5.8595 & 5.2380 & 5.7308 & 7.6119 & 7.2814 & 4.9252 \\
\hline \multicolumn{2}{|c|}{ Ecological footprint } & 3.2954 & 5.0315 & 5.7516 & 6.7969 & 6.1728 & 6.7012 & 8.5630 & 8.2269 & 5.8858 \\
\hline
\end{tabular}

According to the dynamic changes of each component of ecological footprint, the cultivated land footprint keeps a continuous downward trend, from $0.1968 \mathrm{hm}^{2}$ in 2006 to 0.1225 $\mathrm{hm}^{2}$ in 2014 , with a decrease rate of $37.8 \%$. The footprints of grassland, water area and forest land gradually increase in a small fluctuations, with an increase rate of $18.7 \%, 19.7 \%$ and $24.2 \%$ respectively, while the footprint of forest land gradually stabilize at about $0.064 \mathrm{hm}^{2}$, indicating that people's life has been gradually improved, consumption structure upgrading, construction land is $0.3886 \mathrm{hm}^{2}$ in 2014 remained at a high level (the world average is $0.06 \mathrm{hm}^{2}$ ), The fossil energy footprint increased rapidly from $2.3311 \mathrm{hm}^{2}$ in 2006 to $7.6119 \mathrm{hm}^{2}$ in 2012 with an increase of $226.5 \%$, and then declined sharply from 2013 with a decrease of $35.3 \%$, it was $4.9252 \mathrm{hm}^{2}$ in 2014 . That indicates industrialization and urbanization rapidly promote the economic development of the demonstration area, per capita GDP has been in the level of 5000-10000 US dollars, economic development has transfer from factors to efficiency driven and gradually get into the stage of innovation.

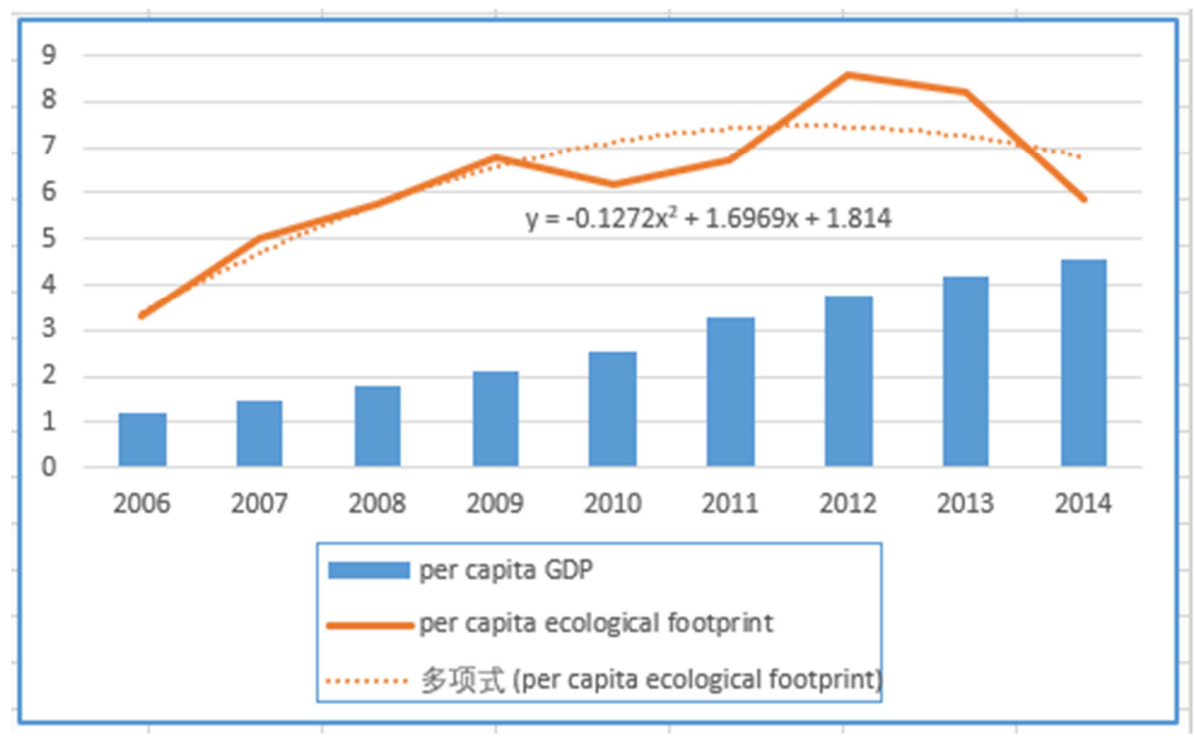

Figure 1. Scatter diagram of per capita GDP and per capita ecological footprint of Jing-men.

In terms of the structure, taking 2012 and 2014 as examples, the proportion of cultivated land was $(1.4 \% ; 2.1 \%)$, grassland $(2.1 \% ; 3.6 \%)$, water area $(1.8 \% ; 2.9 \%)$, forest land $(0.8 \%$; $1.1 \%)$, construction land $(4.8 \% ; 6.6 \%)$, fossil energy land $(88.9 \% ; 83.7 \%)$, fossil energy accounted for more than $80 \%$. The linear experience of per capita ecological footprint and fossil energy footprint was simulated by scatter diagram (Figure 2), the regression equation is: $\mathrm{Y}_{\text {per capita }}=0.969 \mathrm{x}_{\text {fossil }}+$
$1.157+\varepsilon,\left(\mathrm{R}^{2}=0.9942\right.$, significant at the level of 0.001$)$, and the fossil energy footprint and per capita ecological footprint are very significantly correlated, which shows that the development of the demonstration area depends on the combination of resources, environment and fossil energy during the sample period, this indicates the direction for changing the energy consumption structure and reducing the deficit of ecological footprint. 


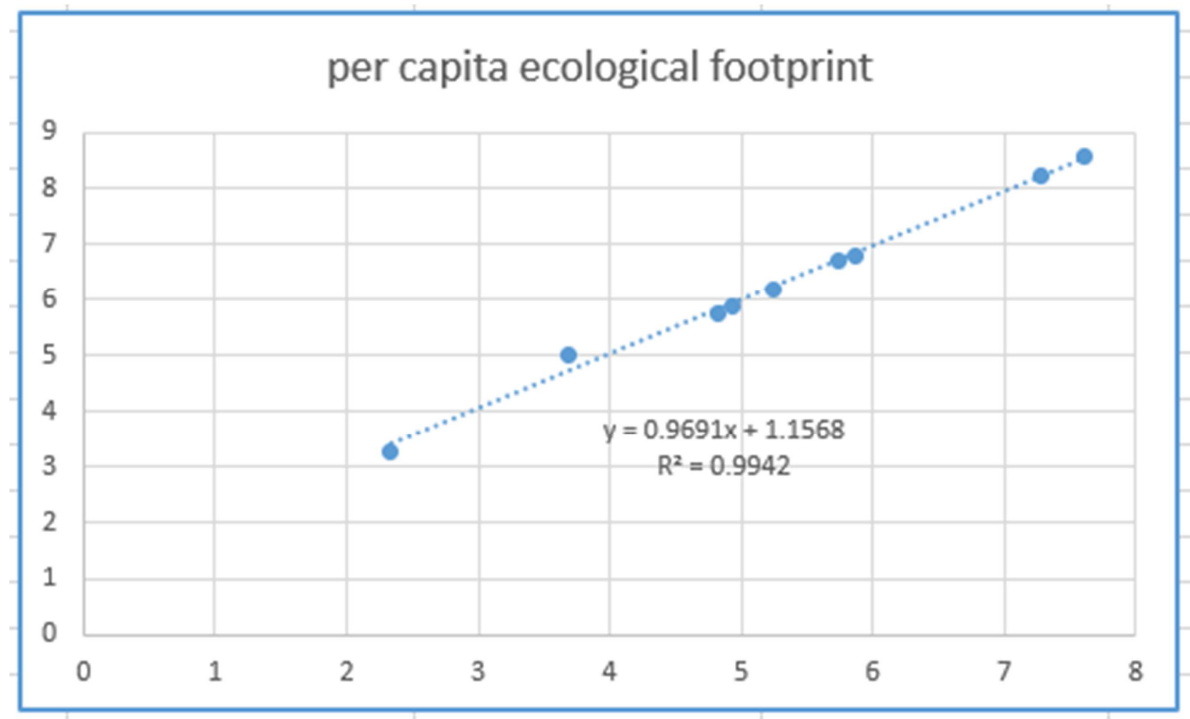

Figure 2. The fossil energy and per capita ecological footprint scatter plots.

\subsection{Dynamic Analysis of Per Capita Ecological Carrying Capacity in Jing-men City}

From table 2, it can be seen that the ecological carrying capacity of Jing-men City has maintained an upward trend from $1.3769 \mathrm{hm}^{2}$ in 2006 to $1.4895 \mathrm{hm}^{2}$ in 2014 after continuously increasing since from 1995 to 2005 with a net increase of $0.1126 \mathrm{hm}^{2}$ and an increase of $8.2 \%$ [9]. In terms of composition, except grass land and construction land, the cultivated land, forest land and water area have respectively increased with $5.2 \%, 16.2 \%$ and $13 \%$ in different degree, which indicates that the cultivated land protection policy has been strictly implemented, the land has been actively developed and consolidated in the demonstration area during the sample period, the number of cultivated land has increased slightly, the agricultural science and technology has been popularized and implemented, so that the land production capacity has been improved to a certain extent, With the implementation of Chang-Fang-Lin project and the construction of ecological city, the bearing capacity of the forest land has been greatly improved. The space of improving the ecological carrying capacity is very limited in quantity due to the mutual exclusion and limitation of land use. Science and technology are the fundamental ways to tap the potential production of land. In terms of the composition of ecological carrying capacity, forest land is the largest component of ecological carrying capacity in Jing-men City, followed by cultivated land and construction land, accounting for $98.3 \%$ in 2014, water area and grassland are $1.4 \%$ and $0.3 \%$ respectively. The ecological carrying capacity and its composition point out the direction for the development in the future and functional orientation of the city, and provide the reference for the selection of the industries transfer.

Table 2. The per capita ecological carrying capacity of Jing-men after the adjustment during 2006-2014 (hm $\left.{ }^{2}\right)$.

\begin{tabular}{llllll}
\hline Land type & Area & Forest & Water area & Grass & Construction \\
\hline Yield & 2.24 & 3.29 & 1 & *Real per capita \\
Equilibrium & 2.52 & 1.26 & 0.37 & 0.2 & 2.24 \\
2006 & 0.4432 & 0.5717 & 0.0184 & 0.46 & 2.51 \\
2007 & 0.444 & 0.5784 & 0.0184 & 0.0046 & 0.3392 \\
2008 & 0.4466 & 0.5834 & 0.0183 & 0.0046 & 0.339 \\
2009 & 0.4503 & 0.5895 & 0.0183 & 0.0046 & 0.3383 \\
2010 & 0.4448 & 0.5944 & 0.0209 & 0.0046 & 0.3377 \\
2011 & 0.4534 & 0.6073 & 0.0209 & 0.0045 & 0.3349 \\
2012 & 0.4678 & 0.6259 & 0.0209 & 0.0045 & 1.3769 \\
2013 & 0.4674 & 0.6398 & 0.0209 & 0.0045 & 0.3342 \\
2014 & 0.4666 & 0.6644 & 0.0208 & 0.0045 & 0.3336 \\
\hline
\end{tabular}

Note:* Indicates it has deducted $12 \%$ for biodiversity conservation

\subsection{Measurement of Ecological Pressure}

\subsubsection{Contradiction Between Ecological Supply and Demand}

It can be seen from table 3 that other types of land were in deficit except cultivated and forest land, the biological production land were in surplus overall in 2006-2014. It indicates that the consumption mode meeting the basic survival was sustainable, meeting the development and enjoyment needs was not sustainable in the demonstration area. The ecological deficit indicates that the regional ecology is unsafe and we have crossed the ecological red line in utilization of nature. fossil energy land accounting for $96.4 \%$ and $94.8 \%$ in 2012 and 2014 is the largest deficit component. 
The fossil energy footprint in the sample period is the root cause of the ecological deficit in the demonstration area.

Table 3. Ecology surplus of 2006-2014 in Jing-men ( $\mathrm{hm}^{2}$, year).

\begin{tabular}{|c|c|c|c|c|c|c|c|c|c|}
\hline Land Type & 2006 & 2007 & 2008 & 2009 & 2010 & 2011 & 2012 & 2013 & 2014 \\
\hline Arable & 0.2464 & 0.2853 & 0.2742 & 0.2834 & 0.2911 & 0.3128 & 0.3398 & 0.3434 & 0.3440 \\
\hline Forest & 0.3938 & 0.2595 & 0.4276 & 0.4201 & 0.4186 & 0.4142 & 0.4429 & 0.4478 & 0.4533 \\
\hline Water area & -0.1298 & -0.3869 & -0.1336 & -0.1215 & -0.1405 & -0.1971 & -0.1416 & -0.1465 & -0.1527 \\
\hline Grass & -0.0476 & -0.0700 & -0.0642 & -0.0699 & -0.0459 & -0.0527 & -0.0589 & -0.0596 & -0.0603 \\
\hline Building & -0.0502 & -0.0463 & -0.0483 & -0.0492 & -0.0585 & -0.0691 & -0.0805 & -0.0647 & -0.0554 \\
\hline Fossil & -2.3311 & -3.6887 & -4.8159 & -5.8595 & -5.2380 & -5.7308 & -7.6119 & -7.2814 & -4.9252 \\
\hline Supply & -1.9185 & -3.6471 & -4.3604 & -5.3965 & -4.7732 & -5.3227 & -7.1103 & -6.7609 & -4.3963 \\
\hline
\end{tabular}

\subsubsection{Calculation of Ecological Pressure Intensity}

In order to directly reflect the degree of "stress" on the regional ecosystem to make up the defect of absolute value of ecological deficit, the ecological pressure index is selected to measure the intensity of regional ecological pressure. The formula is the ratio of regional ecological footprint and the ecological carrying capacity: $\mathrm{ep}=\frac{\mathrm{ef}}{\mathrm{ec}}(4)$. According to the ecological security standard of WWF: when $0<$ ep $<1$, the ecology supply was greater than the demand, and it was in relatively safe state of development and utilization, when ep $=1$, it was in a critical state of sustainable development, when ep $>1$, the supply and demand of resources were unbalanced, the ecology was in unsustainable, the security was threatened. The greater the value of ep the greater the pressure of ecological security: when $1.5>\mathrm{ep}>1.0$, it is "less safe", when $2.0>$ ep $>1.5$, it is "very unsafe", when ep $>2$, it is "extremely unsafe". We can be seen from table 4 , in the sample period, the minimum ecological pressure index of the demonstration area is 2.3933 in 2006 and the maximum is 5.8945 in 2012, the ecology is in "extremely unsafe".

Table 4. The ecological deficit, ecological pressure index and coordination index.

\begin{tabular}{|c|c|c|c|c|c|c|c|c|c|}
\hline Index Type & 2006 & 2007 & 2008 & 2009 & 2010 & 2011 & 2012 & 2013 & 2014 \\
\hline deficit & 1.9185 & 3.6471 & 4.3604 & 5.3965 & 4.7732 & 5.2809 & 7.1103 & 6.7609 & 4.3963 \\
\hline pressure & 2.3933 & 3.6346 & 4.1341 & 4.8537 & 4.4105 & 4.7180 & 5.8945 & 5.6119 & 3.9516 \\
\hline Coordination & 1.3082 & 1.2294 & 1.2071 & 1.1812 & 1.1964 & 1.1856 & 1.1532 & 1.1599 & 1.2148 \\
\hline
\end{tabular}

\subsubsection{Calculation of Ecological Coordination Index}

The same ecological deficit and ecological pressure index have different meanings for developed and underdeveloped regions. In order to reflect the relationship more accurately between ecological footprint and regional resource endowment, ecological coordination index is introduced DS: $\mathrm{DS}=\frac{\mathrm{EF}+\mathrm{EC}}{\sqrt{\mathrm{EF}^{2}+\mathrm{EC}^{2}}}(5)$. The closer DS is to 1, the worse the degree of regional coordinated development is; the closer DS is to 1.414 , the better the degree of coordination is; when $\mathrm{DS}=1.414$, demand and supply is in balance, and the degree of coordinated development is in the best state. When $1 \leq \mathrm{DS}<1.414$, EF $>\mathrm{EC}$, the regional ecological demand is greater than the supply, the development is in an ecological uncoordinated state; when $1 \leq \mathrm{DS}<1.414, \mathrm{EF}<\mathrm{EC}$, the ecological demand is less than the supply, the region is yet to be developed. From 2006 to 2014, the ecological coordination index of Jing-men city (Table 4) shows the ecological coordination index 1.3082 was the highest in 2006, then decreased year by year to the lowest point in 2012, which was 1.1532. After 2013, it gradually picked up, which was 1.2146 in 2014. Although the coordination degree was in a very poor state, it began to recover.

\subsubsection{Dynamic Analysis of Ecological Footprint of Ten Thousand Yuan GDP}

Due to the strong ecological directivity of the core indicators of the ecological footprint model, there are certain defects that comprehensively reveals the contradictions between economic and social development and resources and environment, we introduce ecological footprint of 10000 yuan GDP reflecting the effectiveness of resources using in specific regions, it can more accurately reflect the real contradictions faced by the industrial undertaking area of the Yangtze River Economic Belt in the development process, and explore the space for released pressure. The footprint of Ten-Thousand Yuan GDP of Jing-men demonstration area (Table 5) has experienced a process of first rising and then gradually declining. From 2008 to 2014, it dropped to $1.2975 \mathrm{hm}^{2}$. It shows that Jing-men City has gotten some achievements in energy conservation, emission reduction and industrial structure optimization in the past ten years. Human resources, technology, capital and other functions have been gradually exerted in the economic development process. Resource utilization has been gradually changing to intensive mode. And the utilization efficiency of resources and energy has been greatly improving. However, compared with other regions of the whole country and the Yangtze River economic belt, there is still a big gap. In 2009, the GDP footprint of Shanghai was $0.026 \mathrm{hm}^{2}$, about 1/50 of Jing-men. If the level of science and technology in Shanghai in 2009 is used to create the wealth of Jing-men in 2014 , only $0.117 \mathrm{hm}^{2}$ per capita ecological footprint is needed, the ecological carrying capacity of Jing-men is $1.4895 \mathrm{hm}^{2}$.- 
Table 5. Jing-men ecological footprint of Per Ten-Thousand Yuan GDP.

\begin{tabular}{lllll}
\hline Year & $\begin{array}{l}\text { Per capita ecological footprint } \\
\mathbf{h ~ m}^{\mathbf{2}} \text { ) }\end{array}$ & $\begin{array}{l}\text { GDP (hundred million } \\
\text { yuan/ten-thousand people) }\end{array}$ & $\begin{array}{l}\text { Footprint of per ten thousand yuan } \\
\text { GDP }\left(\mathbf{h m}^{\mathbf{2}}\right)\end{array}$ & $\begin{array}{l}\text { Per capita GDP } \\
\text { (ten-thousand yuan }\end{array}$ \\
\hline 2006 & 3.2954 & 346.54 & 2.6988 & 1.2211 \\
2007 & 5.0315 & 416.42 & 3.4303 & 1.4668 \\
2008 & 5.7516 & 513.96 & 3.1838 & 1.8065 \\
2009 & 6.7969 & 600.1 & 3.2283 & 2.1054 \\
2010 & 6.1728 & 730.07 & 2.4297 & 2.5405 \\
2011 & 6.7012 & 942.59 & 2.0474 & 3.2730 \\
2012 & 8.5630 & 1085.26 & 2.2765 & 3.7615 \\
2013 & 8.2269 & 1202.61 & 1.9751 & 4.1653 \\
2014 & 5.8858 & 1310.59 & 1.2975 & 4.5363 \\
\hline
\end{tabular}

\subsubsection{A Comparative Study on the Ecological Sustainability of the Industrial Undertaking Area of the Yangtze River Economic Belt at the Provincial Scale}

In this paper, the ecological sustainability of the industrial undertaking area of the Yangtze River economic belt at the provincial scale is compared with that of Shanghai, the whole country, Jing-men and downstream regions. In order to improve the reliability of the comparison, the same or similar annual data of the comparison region is selected, and the calculation model is the same as that of these papers [11-19] (Table 6). Except Yunnan province, the ecological deficit of other provinces in the industrial undertaking area is in varying degrees, the ecological footprint of Chongqing $\left(3.058 \mathrm{hm}^{2}\right)$ and Anhui $\left(2.758 \mathrm{hm}^{2}\right)$ is higher than the national average $\left(2.43 \mathrm{hm}^{2}\right)$, Sichuan is somewhat the same as the whole country, and the ecological footprint of the other five provinces is lower than the whole country. Besides Chongqing and Hubei, the per capita GDP is slightly higher than the national average, the other six provinces are lower than the national average. From the perspective of global development, high level development is at the cost of high ecological footprint. Up to now, no country has achieved high level development and maintained a sustainable ecological footprint. The future economic growth (Development) of industrial undertaking area is likely to be similar to Jing-men demonstration area, which is consistent with the Environmental Kuznets inverted U hypothesis. It is currently at the left end of the inverted U curve (Jing-men is at the upper right end and Shanghai is at the lower right end), the per capita ecological footprint of the demonstration area was $8.563 \mathrm{hm}^{2}$ when it crossed the turning point of the curve in 2012, and the per capita ecological footprint of some developed countries entered the declining stage when it exceeded $5.0 \mathrm{hm}^{2}$. Besides Yunnan $\left(1.230 \mathrm{hm}^{2}\right)$ is higher than the national $(0.87$ $\mathrm{hm}^{2}$ ), the other seven provinces and one city are lower than the national average level, and Anhui, Hubei, Guizhou and Chongqing are less than $1 / 2$ of the national average level. Except Jiangxi and Hunan, the ecological pressure of other is greater than the national level. Yunnan has better ecological coordination, Jiangxi and Guizhou are slightly better than the whole country, and other regions are extremely poor. The industrial undertaking area generally highlights the ecological vulnerability characteristics of "low deficit, great pressure and poor coordination". If the future economic development of the area is still driven by factors or driven by efficiency slowly, the per capita ecological footprint will continue to increase, while the ecological carrying capacity will increase slowly in the same period. When the Yangtze River economic belt becomes the new economic support of our country, the entire economic belt will face more severe problems of ecological deficit.

Although the provincial scale Ten-Thousand Yuan GDP footprints of the industrial undertaking area are significantly lower than the national level $\left(1.210 \mathrm{hm}^{2}\right)$, compared with the downstream industry transfer out area of Shanghai $0.026 \mathrm{hm}^{2}$, the gap is very wide. After 2012, the ecological footprints of Jing-men demonstration area continued to decline, and the economy maintained a rapid growth. The Ten-Thousand Yuan GDP footprints dropped to the lowest point in recent 10 years in 2014, It undoubtedly provides reference and enlightenment of sustainable development for the industrial undertaking area.

Table 6. The comparisons of interregional ecological sustainability.

\begin{tabular}{|c|c|c|c|c|c|c|c|}
\hline Region & Year & $\begin{array}{l}\text { *Ecological } \\
\text { footprint }\left(\mathrm{hm}^{2}\right)\end{array}$ & $\begin{array}{l}\text { Ecological carrying } \\
\text { capacity* }\end{array}$ & $\begin{array}{l}\text { Ecological } \\
\text { surplus }\left(\mathrm{hm}^{2}\right)^{*}\end{array}$ & $\begin{array}{l}\text { Ecological } \\
\text { pressure index* }\end{array}$ & $\begin{array}{l}\text { Ecological } \\
\text { coordination } \\
\text { index* }\end{array}$ & $\begin{array}{l}\text { Ten housand } \\
\text { yuan GDP } \\
\text { footprint }\left(\mathrm{hm}^{2}\right)\end{array}$ \\
\hline China & 2010 & 2.43 & 0.87 & -1.56 & 2.79 & 1.279 & 1.21 \\
\hline Jiangxi & 2013 & 1.512 & 0.615 & -0.9 & 2.46 & 1.303 & 0.477 \\
\hline Anhui & 2013 & 2.758 & 0.344 & -2.41 & 8.01 & 1.116 & 0.87 \\
\hline Hubei & 2011 & 2.019 & 0.391 & -1.63 & 5.16 & 1.172 & 0.426 \\
\hline Hunan & 2013 & 1.01 & 0.586 & -0.42 & 1.72 & 1.367 & 0.302 \\
\hline Sichuan & 2012 & 2.434 & 0.483 & -1.95 & 4.04 & 1.175 & 0.552 \\
\hline Yunnan & 2009 & 1.23 & 1.58 & 0.35 & 0.78 & 1.403 & 0.709 \\
\hline Guizhou & 2011 & 1.044 & 0.405 & -0.64 & 2.58 & 1.294 & 0.776 \\
\hline Chongqing & 2012 & 3.058 & 0.435 & -2.62 & 7.03 & 1.131 & 0.782 \\
\hline Shanghai & 2009 & 6.505 & 0.179 & -6.33 & 36.3 & 1.027 & 0.026 \\
\hline Jing-men & 2014 & 5.886 & 1.49 & -4.396 & 3.95 & 1.248 & 1.298 \\
\hline
\end{tabular}

Notes:*Data are from the literature [10]-[18], and got by calculating and sorting. 


\section{Conclusion}

(1) The dynamic change of the per capita ecological carrying capacity in Jing-men demonstration area shows that the basic way to improve the regional carrying capacity is to improve the landing rate of science and technology, develop efficient ecological agriculture.

(2) The industrial undertaking area belongs to the fragile ecological area with the characteristics of continuous expansion trend of ecological deficit, high ecological pressure and poor coordination. The development depended on the combination of resources and environment is not sustainable. its track is consistent with the Environmental Kuznets inverted U curve.

(3) The Ten-Thousand Yuan GDP footprint of the industrial undertaking area is 10 to 50 times higher than that of the industrial transfer out area although it has gradually declined, and that of Jing-men is higher than the national average level.

\section{Discussion}

(1) Reasonably adjust the land use structure and industrial structure, take the planning of the main functional area as the upper plan, realize the deep integration of the primary secondary and tertiary industries with selecting the industries with comparative advantages and taking it as the support, and upgrade the industrial structure to the three, two, one optimization.

(2) The industrial undertaking area should be moderately develop within the ecological red line and continue to do a good job in the ecological barrier in the middle and upper reaches of the Yangtze River, prevent unreasonably developing and utilizing, should be formulate industrial transfer plans, compile industries to "prohibited catalogue" and introduce "negative list" to control the transfer of the polluting industries, avoid "pollution undertaking"; should be vigorously develop renewable green energy, improve energy consumption structure, should be promote the rational flow of ecological carrying capacity and ecological footprint by making full use of domestic and international markets to reduce ecological deficit.

(3) Adhere to the principle of "green water and mountains" as well as "gold mountains" and the purpose of realizing people's all-round development, make use of the late development advantages of the industrial undertaking area, develop circular economy with scientific and technological innovation to improve the agricultural and industrial ecological efficiency, incorporate the industrial ecological efficiency into the assessment index system of green development of the undertaking area's government and enterprises to make the industrial undertaking area cross the turning point of Kuznets inverted U-shaped curve with low level ecological footprint, then realize green development.

\section{Fund Project}

Innovation Engineering Project of Chinese Academy of
Agricultural Sciences (523-1)

\section{References}

[1] Lu Da Dao. The scientific basis of the general layout of China's industrial productivity in 2000 [J]. Geosciences, 1986, 66 (2): 375-384.

[2] Lu Da Dao. Building economic belt is the best choice for economic development layout: the great potential of economic development of Yangtze River economic belt $[\mathrm{J}]$ Geosciences, 2014, 34 (7): 769-772.

[3] Western forum. On the development of the Yangtze River economic belt under the "new normal"--Summary of the keynote speech of the Yangtze River Economic Belt summit forum [J]. Western forum, 2015, (01): 23-41.

[4] Wang Keliang, Meng Xiangrui, Yang Baochen, et al. Study on industrial ecological efficiency of Yangtze River Economic Belt Based on environmental pressure [J]. Resource science, 2015, 37 (7): 1491-1501.

[5] Wei Xiaoxu, Yan Changzhen. Research progress of ecological carrying capacity evaluation method [J]. Journal of earth environment, 2019, 10 (05): 441-452.

[6] Zhao Dong-sheng, Guo Cai-yun, Zheng du, et al. Progress in the study of ecological carrying capacity [J]. Acta ecologica sinica, 2019, 39 (02): 399-410.

[7] Wackernagel M, Lean L, Hobson C B. Evaluating the use of national capital with the ecological footprint [J]. AMBIO, 1999, 28 (7): 604-612.

[8] Gao Lian, Zhou Yong, Li Qing, et al. Analysis of sustainable utilization of cultivated land in Hubei Province Based on Ecological Footprint Theory [J]. Land and natural resources research, 2008 (4): 45-47.

[9] Liu YC, Li wh. Calculation of ecological footprint equilibrium factors in China based on net primary productivity $[\mathrm{J}]$. Journal of ecology and rural environment, 2010, 26 (5): 401-406.

[10] Wu Hao, Fang Chaoyang. Calculation and analysis of ecological footprint of Jiangxi Province in 2004-2013 [J]. Jiangxi science, 2015, 33 (3): 428-434.

[11] Su Zilong, Yuan Guohua, Zhou Wei. Evaluation of land ecological carrying capacity in Anhui Province based on improved 3D ecological footprint model [J]. Water and Soil Conservation Research, 2020, 27 (03): 256-262.

[12] Li Li, Su Weici, Liu can, et al. Dynamic analysis of ecological footprint in Guizhou Province in recent years [J]. Soil and water conservation research, 2014, 21 (4): 251-255.

[13] Cao Sheng, Zhou Weijun, Luo Si ying, et al. Evaluation of ecological sustainability in hunan province based on ecological footprint. Agricultural Science \& Technology, 2017, 18 (05): 877-879+887.62.

[14] Yang Quanwu, Tu Jianjun, Hou Rui, et al. Dynamic evolution characteristics of ecological footprint and ecological carrying capacity in Chongqing [J]. Hubei agricultural science, 2015, 54 (16): 3918-3922. 
[15] Zhang Qun, Guo Huijun, Yang Dong, et al. Evaluation of ecological footprint and ecological carrying capacity: a case study of Yunnan Province [J]. Exploration of economic problems, 2015. (7): 23-29.

[16] Feng Fang, JIN Shuang, Huang Qiaohua, et al. Evaluation of ecological security in Hubei Province based on the energy value-ecological Footprint model [J]. Frozen Glaciers, 2018, 40 (03): 634-642.
[17] Qiu gaohui, Guangjia. Dynamic evaluation and trend prediction of regional ecological security: a case study of Sichuan Province [J]. Ecological economy, 2015, 31 (4): 129-132.

[18] He Caihong, Wu Kaiya, Hu Shuheng, et al. Calculation and dynamic analysis of ecological footprint in Shanghai from 2000 to 2009 [J]. Journal of Hefei University of Technology (NATURAL SCIENCE EDITION), 2012, 35 (2): 268-273. 